\title{
The Incidence of Abortion in Nigeria
}

\section{By Akinrinola \\ Bankole, Isaac F. \\ Adewole, Rubina \\ Hussain, Olutosin \\ Awolude, Susheela \\ Singh and Joshua \\ O. Akinyemi}

Akinrinola Bankole is director of international research, Rubina Hussain is research associate and Susheela Singh is vice president for research-all at the Guttmacher Institute, New York. Isaac F. Adewole is vice chancellor and professor, and Olutosin Awolude is a consultant and lecturer, Department of Obstetrics and Gynaecology; and Joshua $O$. Akinyemi is a lecturer, Department of Epidemiology and Medical Statistics-all at the University of Ibadan, Nigeria.

\begin{abstract}
CONTEXT: Because of Nigeria's low contraceptive prevalence, a substantial number of women have unintended pregnancies, many of which are resolved through clandestine abortion, despite the country's restrictive abortion law. Up-to-date estimates of abortion incidence are needed.
\end{abstract}

METHODS: A widely used indirect methodology was used to estimate the incidence of abortion and unintended pregnancy in Nigeria in 2012. Data on provision of abortion and postabortion care were collected from a nationally representative sample of 772 health facilities, and estimates of the likelihood that women who have unsafe abortions experience complications and obtain treatment were collected from 194 health care professionals with a broad understanding of the abortion context in Nigeria.

RESULTS: An estimated 1.25 million induced abortions occurred in Nigeria in 2012, equivalent to a rate of 33 abortions per 1,000 women aged 15-49. The estimated unintended pregnancy rate was 59 per 1,000 women aged 15-49. Fifty-six percent of unintended pregnancies were resolved by abortion. About 212,000 women were treated for complications of unsafe abortion, representing a treatment rate of 5.6 per 1,000 women of reproductive age, and an additional 285,000 experienced serious health consequences but did not receive the treatment they needed.

CONCLUSION: Levels of unintended pregnancy and unsafe abortion continue to be high in Nigeria. Improvements in access to contraceptive services and in the provision of safe abortion and postabortion care services (as permitted by law) may help reduce maternal morbidity and mortality. International Perspectives on Sexual and Reproductive Health, 2015, 41(4):170-181, doi:10.1363/4117015

Induced abortion is illegal in Nigeria except when performed to save a woman's life. Both the penal code, which is generally applied in the country's northern states, and the criminal code, which generally applies in the southern states, allow this exception, and both regions specify similar criminal penalties for noncompliance. ${ }^{1}$ Yet pregnancy terminations are quite common, and because they are often performed clandestinely or by unskilled providers, most are unsafe. ${ }^{2}$ The first national study to examine the incidence of abortion estimated that in 1996, about 610,000 abortions, or 25 per 1,000 women aged 15-44, occurred in Nigeria. ${ }^{3}$ A decade later, another study noted that if the abortion rate had not changed since 1996, then 760,000 abortions would have occurred in 2006, given the increase in Nigeria's population during this period. ${ }^{4}$

Since the release of the 1996 estimates, the Nigerian government and other stakeholders have initiated a number of policies and programs to improve the reproductive health of women in the country. Notable among them are the government's efforts to achieve the United Nations Millennium Development Goals, including Goal 5, to improve maternal health. This goal has two targets: to reduce the maternal mortality ratio by $75 \%$ between 1990 and 2015, and to provide universal access to reproductive health by 2015. A 2010 government report concluded that progress toward achieving these targets has been slow, and that the modest progress that has been made in reducing maternal mortality has not been accompanied by improvements in other indicators, such as family planning uptake and the proportion of births attended by skilled health workers. ${ }^{5}$

In the hopes of better understanding the scale of clandestine abortion and related reproductive health issues facing Nigerian women, we present new estimates of the incidence of induced abortion in Nigeria, at the national level and for each of the country's six geopolitical zones.

\section{METHODS}

\section{Data Sources}

We produced our estimates using the Abortion Incidence Complications Methodology (AICM), an indirect approach that has been used to estimate the incidence of abortion in more than 15 countries. ${ }^{6-9}$ The methodology relies on data collected through two surveys: a Health Facilities Survey, which gathers information from facilities that treat postabortion patients (i.e., women with complications from induced or spontaneous abortions), and a Health Professionals Survey, which collects information about abortion provision from knowledgeable key informants. These surveys are described in detail below. In addition, we used fertility and other data from the 2013 Nigeria Demographic and Health Survey (NDHS) ${ }^{10}$ and population estimates from the United Nation's 2012 revision of the 
TABLE 1. Number of surveyed facilities that provided postabortion care, and estimated total number of facilities that provided such care, by facility type, according to geopolitical zone, Health Facilities Survey, 2012

\begin{tabular}{|c|c|c|c|c|c|c|c|c|c|c|c|c|c|c|c|c|}
\hline \multirow[t]{3}{*}{ Facility type } & \multicolumn{8}{|c|}{ Surveyed } & \multicolumn{8}{|c|}{ Estimated totals } \\
\hline & \multicolumn{6}{|c|}{ Geopolitical zone } & \multirow[t]{2}{*}{ All } & \multirow{2}{*}{$\begin{array}{l}\% \\
\text { distri- } \\
\text { bution }\end{array}$} & \multicolumn{6}{|c|}{ Geopolitical zone } & \multirow[t]{2}{*}{ All } & \multirow{2}{*}{$\begin{array}{l}\% \\
\text { distri- } \\
\text { bution }\end{array}$} \\
\hline & $\begin{array}{l}\text { North } \\
\text { West }\end{array}$ & $\begin{array}{l}\text { North } \\
\text { East }\end{array}$ & $\begin{array}{l}\text { North } \\
\text { Central }\end{array}$ & $\begin{array}{l}\text { South } \\
\text { West }\end{array}$ & $\begin{array}{l}\text { South } \\
\text { South }\end{array}$ & $\begin{array}{l}\text { South } \\
\text { East }\end{array}$ & & & $\begin{array}{l}\text { North } \\
\text { West }\end{array}$ & $\begin{array}{l}\text { North } \\
\text { East }\end{array}$ & $\begin{array}{l}\text { North } \\
\text { Central }\end{array}$ & $\begin{array}{l}\text { South } \\
\text { West }\end{array}$ & $\begin{array}{l}\text { South } \\
\text { South }\end{array}$ & $\begin{array}{l}\text { South } \\
\text { East }\end{array}$ & & \\
\hline Public/government & 51 & 114 & 62 & 41 & 60 & 41 & 369 & 47.8 & 259 & 487 & 204 & 136 & 173 & 88 & 1,347 & 34.7 \\
\hline Teaching hospital/FMC & 9 & 7 & 8 & 6 & 5 & 12 & 47 & 6.1 & 14 & 7 & 9 & 14 & 10 & 13 & 67 & 1.7 \\
\hline General/specialist hospital & 31 & 44 & 31 & 24 & 26 & 15 & 171 & 22.2 & 115 & 81 & 101 & 68 & 78 & 44 & 487 & 12.6 \\
\hline Cottage hospital/CHC/clinic & 4 & 9 & 17 & 8 & 29 & 11 & 78 & 10.1 & 23 & 14 & 68 & 33 & 85 & 23 & 246 & 6.3 \\
\hline Maternity center & 7 & 54 & 6 & 3 & 0 & 3 & 73 & 9.5 & 107 & 385 & 26 & 21 & 0 & 8 & 547 & 14.1 \\
\hline Private* & 68 & 42 & 76 & 92 & 59 & 66 & 403 & 52.2 & 402 & 190 & 619 & 426 & 441 & 454 & 2,532 & 65.3 \\
\hline Hospital & 36 & 18 & 45 & 84 & 33 & 47 & 263 & 34.1 & 131 & 84 & 327 & 353 & 210 & 245 & 1,350 & 34.8 \\
\hline Clinic/medical center & 9 & 15 & 11 & 6 & 23 & 4 & 68 & 8.8 & 75 & 56 & 91 & 41 & 163 & 24 & 450 & 11.6 \\
\hline Maternity center & 23 & 9 & 20 & 2 & 3 & 15 & 72 & 9.3 & 196 & 50 & 201 & 32 & 68 & 185 & 732 & 18.9 \\
\hline All & 119 & 156 & 138 & 133 & 119 & 107 & 772 & 100.0 & 661 & 677 & 823 & 562 & 614 & 542 & 3,879 & 100.0 \\
\hline
\end{tabular}

*Includes 31 facilities operated by nongovernmental organizations or missions. Notes: Percentages may not total 100.0 because of rounding. FMC=Federal medical center. $\mathrm{CHC}=$ Comprehensive health center.

World Population Prospects in our calculations. ${ }^{11}$ The study was approved by the Guttmacher Institute's institutional review board and by the University of Ibadan Ethical Review Committee.

\section{Health Facilities Survey}

All public and private health facilities that had the capacity to provide postabortion care services were included in the sample frame for the survey. We compiled a list of potentially eligible health facilities using the most recent (2007) National Bureau of Statistics' Directory of Health Establishments in Nigeria, supplemented by information from the 2007 National Health Insurance Scheme and the Ministry of Health's Department of Hospital Services. Slightly more than 5,000 facilities were deemed eligible.

It was important to represent all six of Nigeria's geopolitical zones, because women's social and demographic characteristics vary greatly across the country, particularly between the northern and southern zones. * Therefore, using information from the Nigerian census and the 2008 NDHS, ${ }^{\dagger}$ we grouped the states in each zone into tertiles according to the proportion of women who lived in urban areas, and randomly selected one state per tertile (and thus three states per zone). This yielded a total of 18 states across the country: Kaduna, Kebbi and Jigawa in the North West; Bauchi, Borno and Taraba in the North East; Kwara, Nasarawa and Niger in the North Central; Abia, Anambra and Imo in the South East; Cross River, Edo and Rivers in the South South; and Lagos, Ogun and Ondo in the South West.

A total of 3,125 facilities that potentially provided postabortion care were located in the 18 states. We randomly selected $75 \%$ of public secondary hospitals (general, specialist and district-level), comprehensive health centers, cottage hospitals and public clinics; $40 \%$ of private hospitals, clinics and medical centers (a mixture of secondaryand primary-level facilities); $40 \%$ of public maternity cen- ters (mostly primary-level); and $17 \%$ of private maternity centers (again, mostly primary-level). In addition, because of their large postabortion care caseload, we included all tertiary facilities (teaching hospitals and federal medical centers) in the country, regardless of whether they were located in sampled states. After exclusion of 45 facilities that no longer existed or were not found, the final sample consisted of 1,088 facilities.

Trained interviewers visited each sampled facility between July 2011 and March 2012, and used a standardized questionnaire to conduct a face-to-face interview with a senior staff member knowledgeable about the facility's provision of abortion services. Respondents were chosen on the basis of their seniority as well as their familiarity with abortion-related services at their facility; they either oversaw abortion or postabortion care at the facility, or were the only provider or one of the few providers of such services. Interviewers, with the support of their supervisors, were responsible for using these criteria to locate appropriate respondents. In some instances, the identified respondent was unavailable or was unable to complete an interview. In these cases, the interviewer made multiple attempts to interview the respondent; if this was not possible, the interviewer sought an interview with the next most knowledgeable person, if there was more than one provider.

The response rate for the survey was 98\%. An initial analysis found that 314 facilities in our sample did not offer postabortion care, and two that did offer such services had not responded to a number of key questions; these facilities were removed from our analysis. Of the remaining 772

\footnotetext{
*Residents of the northern zones are largely Muslim, whereas the southern zones' population is primarily Christian. In addition, the proportions of women who live in urban areas and levels of female education are lower in northern zones than in southern ones. Compared with the other zones, the North West and North East zones have lower contraceptive prevalence and higher fertility.
}

†At the time of sampling, the 2013 NDHS was not available. 
facilities, $48 \%$ were in the public sector, and $52 \%$ were private or were operated by nongovernmental organizations or missions (Table 1, page 171). For each geographic zone, we assumed that the proportion of facilities in our sample that did not provide postabortion care was representative of the zone as a whole, and proportionally reduced the universe of facilities that provide such services in the zone, resulting in an estimate that 3,879 facilities provide postabortion care nationally.

Most of the facilities included in this study provided both inpatient and outpatient services (Appendix Table 1, page 177). The majority of high-level government facilities (teaching hospitals, federal medical centers, and general and specialist hospitals) and private facilities had functional manual vacuum aspiration (MVA) equipment; the proportion ranged from $62 \%$ for private maternity centers to $98 \%$ for teaching hospitals and federal medical centers. Fifty percent of cottage hospitals and other community health centers had functioning MVA equipment, but only $10 \%$ of government maternity facilities did. With the exception of government maternity centers, the majority of facilities in each category had staff trained in use of the equipment. All teaching hospitals, federal medical centers, and general and specialist hospitals had surgical wards, as did more than $90 \%$ of private hospitals, clinics and medical centers. Most teaching hospitals and federal medical centers (84\%) also reported having a separate ward for abortion-related services.

Because of staff shortages and inadequate resources, record-keeping is inadequate at facilities in many developing countries. For example, a recent study found medical record-keeping in six tertiary facilities in Nigeria to be poor in both completeness and quality, ${ }^{12}$ and only $46 \%$ of sampled facilities in a 2008 Colombian AICM study were able to provide adequate information for the study year, leading the authors to argue that "data maintained by facilities are currently too incomplete to be the basis of national estimates of abortion incidence."13(p.116) Because we had similar concerns, we did not rely on official facility records to help us determine the number of postabortion care cases or pregnancy terminations at the facility. Instead, we obtained caseload estimates for each facility from the knowledgeable senior staff member who was interviewed for the survey.

Of the 772 surveyed respondents, 52\% were obstetrician/gynecologists, general practitioners, other physicians or medical officers; $33 \%$ were nurses or midwives; $14 \%$ were community health extension workers or community health officers; and fewer than 1\% were other staff (Appendix Table 2, page 178). Fifty-seven percent of respondents had at least 10 years of work experience, $41 \%$ were female and 70\% were aged 30-50 (not shown). In public teaching hospitals and federal medical centers, and in private hospitals, clinics and medical centers, a large majority of respondents were physicians or medical officers (66-72\%; Appendix Table 3, page 178), while in public cottage hospitals, comprehensive health centers and public clinics most respondents were nurses, midwives, community health extension workers or community health officers (74-93\%). General and specialist hospitals and private maternity centers had a more balanced mix of respondents.

All respondents provided informed consent; they did not receive remuneration for participating. Respondents were asked to estimate the number of patients who received postabortion care (for complications of either spontaneous or induced abortion) at their facility as outpatients and inpatients. To accommodate the large variation in facility size and capacity, we offered respondents three time periods (week, month and year) for which to make their estimates, but asked them to answer for only one. They provided estimates for both the average week, month or year, and the past week, month or year. We asked for these two types of estimates to increase the likelihood of accurate recall and of capturing variation within the year. Responses were converted to annual totals and averaged to provide an estimate for the calendar year. Respondents were also asked to estimate the number of induced abortions performed at the facility during the same time periods.

In examining the data from the Health Facilities Survey, we became concerned about the accuracy of some results, because the proportion of facilities that reported providing abortions was very small, regardless of facility type. In the Health Facilities Survey conducted for the 1996 estimate of abortions incidence in Nigeria, 33\% of respondents indicated that their facility provided induced abortion services; ${ }^{3}$ in the current study, only $8 \%$ of respondents reported that their facility performed abortions (Appendix Table 1). Private clinics and medical centers were the most likely to report providing this service (21\%), followed by teaching hospitals and federal medical centers (14\%).

We hypothesized that because of growing social conservatism throughout Nigeria and the inhibiting effects of a new antiabortion stance in the national (and a number of state) legislative houses, some respondents were misclassifying pregnancy terminations-probably intentionally-as cases of postabortion care. The defeat of the 2006 reproductive health bill in the Senate (largely because it was considered an abortion bill), and the 2013 repeal of a 2012 law that, among other things, had expanded the criteria for legal abortion in Imo state, exemplify the increasing level of social conservatism in Nigeria. ${ }^{14}$ Moreover, in a 2009 study, nearly one-third of 49 Nigerian policymakers surveyed said that abortion should not be allowed even to save a woman's life. ${ }^{15}$ Because our respondents' apparent misreporting of the number of abortions performed at their facility would have resulted in our overestimating the number of postabortion care patients treated in Nigeria, we adjusted their estimates in accordance with our experience from a similar study we had conducted (see Appendix, page 179).

\section{Health Professionals Survey}

The Health Professionals Survey was designed to elicit respondents' perceptions regarding various aspects of abortion provision in Nigeria and the potential health con- 
sequences of such abortions; topics included the types of providers from whom women obtain abortions, the likelihood that these abortions result in complications and the likelihood that women obtain treatment at a facility for these complications. Study investigators and the research team prepared a list of health professionals knowledgeable about the conditions of abortion provision and postabortion care. Interviewers and supervisors from each geopolitical zone contributed to the list, ensuring adequate representation of all zones. We drew on membership directories of relevant professional associations to further broaden the list; we intentionally avoided selecting individuals who had participated in the Health Facilities Survey.

The resulting purposive sample of 194 respondents spanned a wide range of professions, including doctors, nurses and midwives (54\%); program managers and health administrators ( $12 \%$ ); policymakers, legal practitioners and activists (16\%); lecturers and researchers (15\%); and other experts (4\%; Appendix Table 2). We included both medical and nonmedical participants because evidence indicates that estimates of the parameters under investigation may differ substantially between these two groups. ${ }^{6}$ The representation of medical providers varied from $44 \%$ in the South South region to $67 \%$ in the South East. About $54 \%$ of the sample was from the north, $75 \%$ were working in the public sector and $43 \%$ either were currently working in rural areas or had done so in the past five years (not shown). All interviews were conducted in person by a small number of trained interviewers using a structured questionnaire.

\section{Analysis}

The first step of our analysis was to estimate the number of women who receive treatment for induced abortion complications in Nigeria's health facilities. Health Facilities Survey respondents were not asked to provide separate estimates for induced and spontaneous abortions, because complications of the two often are difficult to distinguish, and because restrictive abortion laws may deter accurate reporting. Thus, it was necessary to estimate and subtract the number of cases involving complications of spontaneous abortion. To do this, we applied an indirect method based on clinical studies that established the biological pattern of spontaneous abortion. Using this approach, we estimated that the number of miscarriages that occur at 13-22 weeks' gestation (i.e., those likely to require facility-based care) was equal to $3.4 \%$ of the number of live births. ${ }^{6}$

For various reasons, including constraints on access to care, not all women who need care for late spontaneous abortions receive treatment at health facilities. We assumed that among Nigerian women who require such care, the proportion who receive care is the same as the proportion of women giving birth who receive antenatal care in a health facility-41\% in the North West, $49 \%$ in the North East, 67\% in the North Central, 91\% in the South East, $73 \%$ in the South South, 90\% in the South West and $61 \%$ nationally, according to the 2008 NDHS. Using these proxy proportions, we estimated that 142,430 women received care for spontaneous abortion in 2012, and subtracted this number from the total number of postabortion care patients to obtain an estimate of the number treated specifically for complications of induced abortion.

The next methodological step relied on responses of the knowledgeable health professionals. One of three outcomes is likely for women obtaining clandestine abortions: They may experience no health complications, or none serious enough to require care; they may experience complications, but not receive care; or they may have complications and obtain the care they need. Reasons for women's not receiving care include stigma, cost, distance to a health facility and death before having a chance to receive care. Applying a number called a multiplier to the number of women treated for complications of induced abortion accounts for the women who do not need or receive treatment, and produces an estimate of the total number of abortions. For example, a multiplier of 4.0 means that one in four women who had an induced abortion received treatment for complications in a health facility. A small multiplier reflects either that abortion is generally unsafe or that access to medical care is high, whereas a large multiplier indicates that abortion is very safe or that many women do not have access to medical care. We calculated separate multipliers for each region (see Appendix for further details).

Because of the uncertainty inherent in our estimates, we calculated 95\% confidence intervals around the total number of abortion complications (induced and spontaneous) treated in health facilities. We then applied the methodology described above to the low and high estimates of the number of treated complications to produce upper and lower estimates of abortion incidence (number and rate).

\section{RESULTS}

\section{Treatment for Abortion-Related Complications}

After adjustment of the original Health Facilities Survey data (see Appendix), we estimate that 354,400 women were treated for complications of spontaneous or induced abortion in Nigeria in 2012 (Table 2, page 174). Slightly more than half of these women (54\%) were treated in public facilities (not shown); the proportion varied by region, ranging from 34\% in the South South to $78 \%$ in the North East, likely reflecting differences in the availability and accessibility of private-sector facilities. Only in the South South and South East zones did public facilities treat fewer than half of patients who received postabortion care. Nationally, the majority of patients were treated at large hospitals, both in the public sector (59\%) and private sector (56\%). However, the situation varied among regions; for example, in the public sector, the proportion of women treated at hospitals ranged from $35 \%$ in the North Central region to $82 \%$ in the North West region.

After subtracting the number of women who had been treated for complications of late spontaneous abortions, we estimated that 212,000 women were treated for complications associated with induced abortion in Nigeria's 
TABLE 2. Estimated number of women treated for complications of spontaneous or induced abortions, and associated measures, by facility type, according to geopolitical zone, Nigeria, 2012

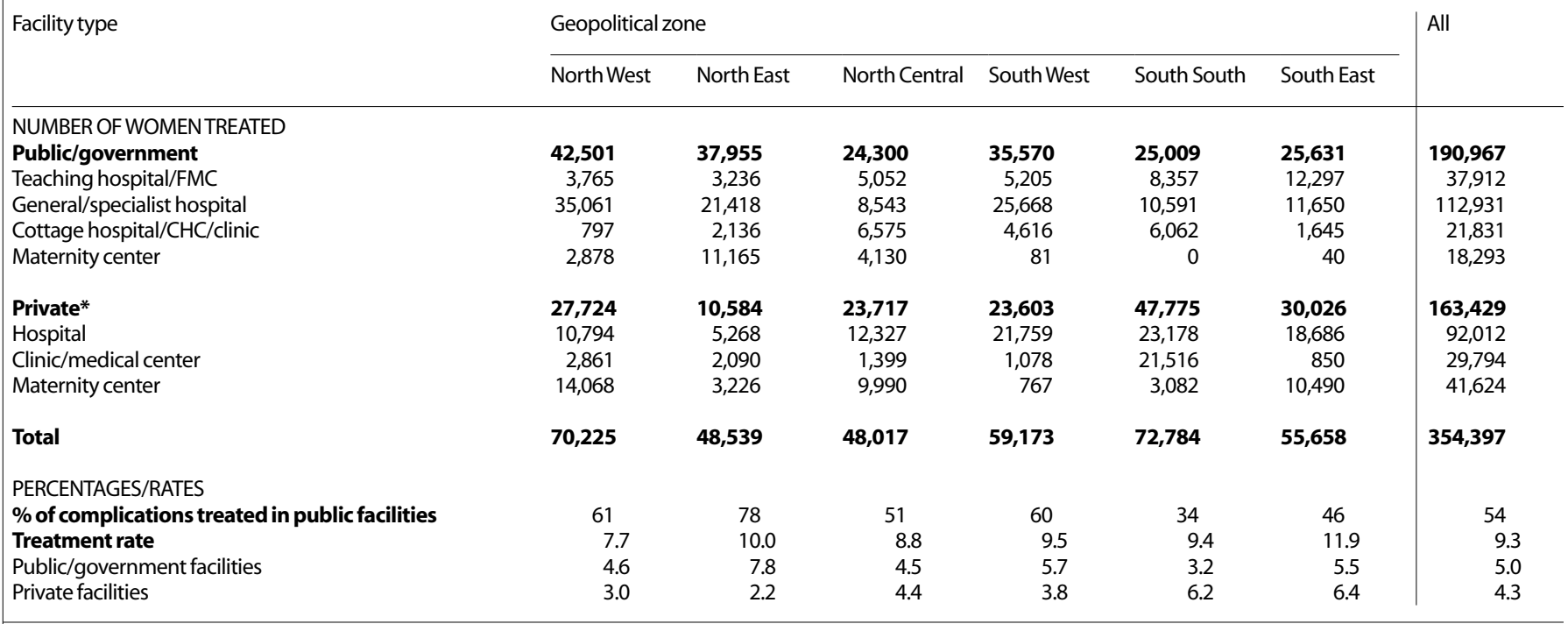

*Includes 31 facilities run by nongovernmental organizations or missions. Notes: All values are adjusted to correct for misclassification. Treatment rate refers to number of women who received treatment in the specified facilities per 1,000 women aged 15-49 in the general population. Sums of values may not equal totals because of rounding. FMC=Federal medical center. $\mathrm{CHC}=$ Comprehensive health center.

health facilities in 2012 (Table 3). These cases accounted for $60 \%$ of all women treated for any abortion-related complication in 2012 (not shown).

However, not every woman who has complications from unsafe abortion serious enough to require treatment in health facilities obtains the care she needs. According to estimates from the Health Professionals Survey, $40 \%$ of women who had an abortion in 2012 had complications warranting treatment in a facility. On the basis of this proportion, we estimate that an additional 285,000 women (or seven per 1,000 women aged 15-49) had abortion complications but did not receive care that year (not shown).

\section{Number and Rates of Induced Abortion}

The multipliers, which account not only for women who did not receive care for complications but also those who did not have complications, ranged from 3.9 in the South East to 8.4 in the North West (Table 3). Application of these multipliers yields an estimate that 1.25 million induced abortions occurred in Nigeria in 2012; our lower and upper estimates are 963,000 and 1.54 million. Overall, we estimate that the national induced abortion rate was 33 per 1,000 women aged 15-49 (confidence interval, 25-40 per 1,000), somewhat higher than the estimated rate of 25 per 1,000 women aged 15-44 (or 23 per 1,000 women

TABLE 3. Measures used to estimate abortion levels, and key indicators of incidence, by geopolitical zone, Nigeria, 2012

\begin{tabular}{|c|c|c|c|c|c|c|c|}
\hline \multirow{2}{*}{ Measure } & \multicolumn{6}{|l|}{ Zone } & \multirow{2}{*}{ All } \\
\hline & North West & North East & North Central & South West & South South & South East & \\
\hline \multicolumn{8}{|l|}{ ABORTION-RELATED } \\
\hline No. of women treated for abortion complications & 70,225 & 48,539 & 48,017 & 59,173 & 72,784 & 55,658 & 354,397 \\
\hline No. of women treated for complications of spontaneous abortion & 27,199 & 16,552 & 20,912 & 35,231 & 21,595 & 20,948 & 142,438 \\
\hline No. of women treated for complications of induced abortion & 43,025 & 31,987 & 27,105 & 23,942 & 51,189 & 34,710 & 211,959 \\
\hline$\%$ of treated complications due to induced abortion & 61 & 66 & 56 & 40 & 70 & 62 & 60 \\
\hline Lower estimate & 300,270 & 182,584 & 117,475 & 98,807 & 178,896 & 84,758 & 962,791 \\
\hline Upper estimate & 420,834 & 275,474 & 177,970 & 229,200 & 250,071 & 183,894 & $1,537,443$ \\
\hline \multicolumn{8}{|l|}{ DEMOGRAPHIC } \\
\hline No. of women aged 15-49 & $11,636,504$ & $5,649,521$ & $5,459,670$ & $6,186,806$ & $4,842,436$ & $4,385,825$ & $38,160,762$ \\
\hline No. of live births & $1,945,456$ & 984,578 & 915,300 & $1,142,895$ & 867,514 & 678,052 & $6,533,794$ \\
\hline Induced abortion treatment rate‡ & 3.7 & 5.7 & 5.0 & 3.9 & 10.6 & 7.9 & 5.6 \\
\hline
\end{tabular}

*Number of abortions per 1,000 women aged 15-49. †Number of abortions per 100 live births. ₹Number of women receiving postabortion care per 1,000 women aged 15-49. Sources:

Abortion-related measures-Health Facilities Survey and Health Professionals Survey. No. of women aged 15-49-reference 11. No. of live births-Calculated from data in reference 10. 
TABLE 4. Selected pregnancy-related measures, and percentage distribution of pregnancies by outcome, all according to geo-political zone, Nigeria, 2012

\begin{tabular}{|c|c|c|c|c|c|c|c|}
\hline Measure & North West & North East & North Central & South West & South South & South East & All \\
\hline No. of pregnancies & $2,731,155$ & $1,433,426$ & $1,260,854$ & $1,551,877$ & $1,276,948$ & 961,421 & $9,215,682$ \\
\hline Pregnancy rate* & 235 & 254 & 231 & 251 & 264 & 219 & 241 \\
\hline Unintended pregnancy rate† & 38 & 64 & 51 & 62 & 100 & 66 & 59 \\
\hline$\%$ of pregnancies that were unintended & 16 & 25 & 22 & 25 & 38 & 30 & 24 \\
\hline \multicolumn{8}{|l|}{ Pregnancy outcomes } \\
\hline Birth from planned pregnancy & 70 & 62 & 65 & 63 & 52 & 58 & 63 \\
\hline Miscarriage of planned pregnancy & 14 & 12 & 13 & 13 & 10 & 12 & 13 \\
\hline Abortion & 13 & 16 & 12 & 11 & 17 & 14 & 14 \\
\hline Birth from unplanned pregnancy & 2 & 6 & 8 & 11 & 16 & 12 & 8 \\
\hline Miscarriage of unplanned pregnancy & 2 & 3 & 3 & 3 & 5 & 4 & 3 \\
\hline Total & 100 & 100 & 100 & 100 & 100 & 100 & 100 \\
\hline
\end{tabular}

*Annual number of pregnancies per 1,000 women aged 15-49. †Annual number of unintended pregnancies per 1,000 women aged 15-49. Note: Sums of percentages may not equal 100 because of rounding.

aged 15-49) in 1996. Because of the large differences in the quality of reporting of clandestine abortion services, the two studies used different adaptations of the AICM, and deriving conclusions from a comparison of the data is difficult. However, the 1996 abortion rate of 23 per 1,000 women 15-49 falls just outside the confidence interval for the 2012 rate, suggesting that abortion incidence may have increased somewhat between 1996 and 2012.

Regional abortion rates varied widely. They were lowest in the North Central and South West zones (27 per 1,000 in each), slightly higher in the North West and South East zones (31 per 1,000 in each) and highest in the North East (41 per 1,000) and South South (44 per 1,000). To further put the number of induced abortions in context, the abortion ratio (number of abortions per 100 live births) was 19 per 100 nationally, and ranged from 14 per 100 in the South West to 25 per 100 in the South South.

\section{Pregnancies and Their Outcomes}

Obtaining a plausible estimate of the number of abortions allowed us to estimate the number of pregnancies that occurred in Nigeria in 2012. This number is the sum of the numbers of induced abortions, births and spontaneous abortions among women aged 15-49. To estimate the number of births, we applied age-specific fertility rates from the NDHS to the number of Nigerian women in fiveyear age-groups. Estimates of spontaneous abortion were calculated according to the formula (derived from clinical studies of pregnancy loss) that the number of spontaneous abortions occurring at five or more weeks' gestation is approximately equal to $20 \%$ of the number of births plus $10 \%$ of the number of induced abortions. ${ }^{16,17}$

These calculations indicate that women aged 15-49 had about 9.22 million pregnancies in Nigeria in 2012 (Table 4). The overall pregnancy rate was 241 pregnancies per 1,000 women in this age-group. The rate was lowest in the South East (219) and highest in the South South (264). The national unintended pregnancy rate was 59 per 1,000 women aged 15-49; regionally, the rate ranged from 38 in the North West to 100 in the South South. Nationally, 24\% of pregnancies in 2012 were unintended; the proportion was lowest in the North West (16\%) and highest in the South South (38\%).

The majority of Nigerian women's pregnancies in 2012 ended in planned births. The proportion was $63 \%$ for the country as a whole, and ranged from $52 \%$ in the South South to $70 \%$ in the North West. About $14 \%$ of pregnancies ended in abortion; the proportion varied from $11 \%$ in the South West to $17 \%$ in the South South. At the national level, about $56 \%$ of unintended pregnancies ended in abortion (not shown); regionally, the proportion was lowest in the South West (43\%) and highest in the North East (64\%) and North West (81\%). Fewer than half of unintended pregnancies in the three southern regions ended in abortion.

\section{DISCUSSION}

\section{Mortality and Morbidity due to Unsafe Abortion}

Nigeria has one of the highest maternal mortality ratios in the world. ${ }^{18}$ Although the government has acknowledged the problem and is committed to improving maternal health, evidence suggests that progress has been limited, and unsafe abortion remains a major contributor to mater-

Table 5. Selected characteristics women aged 15-49, by geographic zone, Nigeria Demographic and Health Survey, 2013

\begin{tabular}{|c|c|c|c|c|c|c|c|}
\hline \multirow[t]{2}{*}{ Characteristic } & \multicolumn{6}{|l|}{ Zone } & \multirow[t]{2}{*}{ All } \\
\hline & $\begin{array}{l}\text { North } \\
\text { West }\end{array}$ & $\begin{array}{l}\text { North } \\
\text { East }\end{array}$ & $\begin{array}{l}\text { North } \\
\text { Central }\end{array}$ & $\begin{array}{l}\text { South } \\
\text { West }\end{array}$ & $\begin{array}{l}\text { South } \\
\text { South }\end{array}$ & $\begin{array}{l}\text { South } \\
\text { East }\end{array}$ & \\
\hline$\%$ living in urban area & 29 & 27 & 27 & 77 & 39 & 70 & 42 \\
\hline$\%$ with $\geq 7$ yrs. of education & 19 & 22 & 45 & 72 & 72 & 74 & 45 \\
\hline$\%$ married & 85 & 81 & 70 & 66 & 55 & 52 & 72 \\
\hline$\%$ Catholic/Protestant & 10 & 16 & 54 & 64 & 97 & 98 & 47 \\
\hline \% Muslim & 90 & 83 & 44 & 35 & 2 & 0.3 & 52 \\
\hline$\%$ using any contraceptive method & 5 & 3 & 14 & 33 & 29 & 27 & 16 \\
\hline$\%$ using a modern method & 4 & 3 & 11 & 23 & 18 & 14 & 11 \\
\hline$\%$ with unmet need for contraception & 11 & 16 & 19 & 12 & 18 & 10 & 14 \\
\hline$\%$ of births unplanned* & 2 & 9 & 10 & 15 & 24 & 18 & 10 \\
\hline$\%$ of births mistimed* & 2 & 8 & 8 & 11 & 20 & 13 & 8 \\
\hline$\%$ of births unwanted* & 0.2 & 1 & 3 & 4 & 4 & 5 & 2 \\
\hline Total fertility rate & 6.7 & 6.3 & 5.3 & 4.6 & 4.3 & 4.7 & 5.5 \\
\hline Wanted fertility rate & 6.5 & 6.1 & 4.8 & 4.2 & 3.9 & 4.3 & 5.2 \\
\hline
\end{tabular}

*In past three years. Source: reference 10. 
nal morbidity and mortality.

In a community-based survey conducted in 2002-2003, $25 \%$ of women who had had an induced abortion reported having had serious complications. ${ }^{19}$ Another study found that women who had been admitted to hospitals for complications of induced abortion had suffered a variety of complications, including retained products of conception (50\%), bleeding (34\%) and fever (34\%). ${ }^{20}$ Two-thirds had had serious complications, such as sepsis, pelvic infections and injury from instruments, and some died.

A recent study recorded 137 maternal near-miss cases* in a six-month period at eight large hospitals across the country, and found that $13(10 \%)$ were due to unsafe abortion. ${ }^{21}$ Another study estimated that in the late 1990s, about 3,000 women died annually from unsafe abortion in Nigeria. ${ }^{20}$ Because this estimate included only women who had died in health facilities, and not those who had died from unsafe abortion before reaching a facility, the actual number of deaths was likely higher.

We estimate that in 2012, about 212,000 women were treated in health facilities for complications of induced abortion, suggesting that unsafe abortion remains an important contributor to maternal morbidity and mortality in Nigeria. In addition, an estimated 285,000 women had complications serious enough to require treatment in health facilities, but did not obtain the care they needed. The impact of unsafe abortion extends beyond morbidity and mortality; there are also social costs to Nigerian women and their households, including the risks associated with breaking the country's restrictive abortion law and the possibility of strong social sanctions.

Furthermore, unsafe abortion imposes a heavy financial burden on both women and Nigeria's fragile health care system. For example, one study estimated that postabortion care cost US\$103 per patient in Nigeria in 2005, amounting to US\$19 million; the average per-case cost for hospital care was US\$132, of which $72 \%$ (US\$95) was borne by women and their households. ${ }^{22}$

\section{Unintended Pregnancy and Abortion}

Findings from this study suggest that unintended pregnancy-the root cause of most abortions-is still occurring at moderately high levels in Nigeria. The high rates of unintended pregnancy and abortion are probably due largely to the combination of low prevalence of contraceptive use (especially use of modern methods) and the high proportion of women who need methods to avoid unwanted births or (particularly in the case of sexually active unmarried young women) to delay their first pregnancy. Women with the latter need are not an insignificant group: According to the 2013 NDHS, $40 \%$ of never-married women aged 15-19 had had sex, and about three-quarters of this group

*A near-miss maternal event is the near-death of a woman from a complication during pregnancy or childbirth or within 42 days of the termination of pregnancy (source: Say L, Souza JP and Pattinson RC, Maternal near miss-towards a standard tool for monitoring quality of maternal health care, Best Practice and Research, 2009, 23(3):287-296). had done so within the past year.

Evidence from national surveys suggests that the number of abortions in Nigeria is likely to remain high in the absence of intervention. According to the 2013 NDHS, Nigerian women aged 15-49 had, on average, more children than they wanted (Table 5). ${ }^{10}$ Although the difference between total fertility and wanted fertility was not large, women in all six geopolitical zones had more children than they desired. The prevalence of contraceptive use remained at virtually the same low level as in the 2008 NDHS-only 16\% of women of reproductive age were using a method, and only $11 \%$ were using a modern method, in $2013 .{ }^{10}$ In addition, $14 \%$ of women aged $15-49-$ and $22 \%$ of sexually active unmarried women in this age group (not shown)-had an unmet need for contraception, meaning that they did not want to have a child in the next two years or wanted no more children at all, but were not using any contraceptive method (Table 5). Women with unmet need commonly cite opposition to contraception (their own, their partner's or that of another person, such as a family member) and fear of side effects as reasons for nonuse. ${ }^{24}$

The high rates of abortion in the North East and South South are likely related to factors that increase women's need for abortion in these regions. The proportion of women in the North East who use contraceptives is the lowest in the country (3\%), and the level of unmet need (16\%) is higher than average. Although the social and demographic characteristics and contraceptive behavior of women in the North East are similar to those of their counterparts in the neighboring North West zone, the abortion rates differ greatly (41 vs. 31 per 1,000 women aged 15-19). This difference, together with the slightly higher rates of total fertility and wanted fertility in the North West compared with the North East, suggest that women in the former zone are more likely than those in the latter to carry their pregnancies to term.

Women in the three southern regions want smaller families (3.9-4.3 children) than do women in the northern regions (4.8-6.5), which may indicate that women in the southern regions have a relatively strong desire to limit their family size. Although the South South ranks second in the proportions of women using any contraceptive method (29\%) and any modern method (18\%), it also has the second highest level of unmet need (18\%). This suggests that compared with women in other regions, those in the South South may be relying on abortion to a greater degree, and on contraception to a lesser degree, to achieve the smaller families they desire.

\section{Limitations}

Like other indirect estimation techniques, the AICM has limitations. The data on the number of postabortion care cases treated in health facilities-a key input variable in our calculation of abortion incidence-are derived from respondents' estimates. We must rely on these estimates because facilities' official records are frequently inaccurate, grossly incomplete or nonexistent. We believe that a shift 
to social and religious conservatism has greatly affected the accuracy of facilities' reporting of abortion provision in Nigeria; while respondents may be able to report reasonably accurate estimates of clandestine abortion services and of postabortion complication care, a comparison of estimates from this study with those from the previous one strongly suggests that many respondents grouped the two services together as postabortion complication cases in their reports, thus greatly reducing the reporting of abortions. Consequently, to calculate abortion estimates more realistically, we had to make several adjustments to ensure realistic abortion estimates. Moreover, to correct for noticeable underestimates and overestimates of postabortion care caseloads in some regions and facilities, we assumed that service provision in these regions and facilities was similar to that in some neighboring regions and facilities. These adjustments likely resulted in a conservative estimate of abortion incidence in Nigeria.

Lastly, lacking any direct information on this topic, we calculated the required multipliers using data on the perceptions of health professionals. While these respondents were carefully chosen and have extensive expertise on abortion-seeking behavior, the resulting multipliers are not exact measures; thus, we present confidence intervals around the estimates of abortion incidence.

\section{Implications for Policies and Programs}

Given the extent to which unsafe abortions are still occurring in Nigeria, there is strong need for the government and local and international stakeholders to make more concerted efforts to ensure that women do not continue to suffer or die needlessly from unsafe abortion. Since unintended pregnancy is the reason for most abortions, the most important-and least expensive-step is to promote access to contraceptive services to prevent such pregnancies. Programmatic efforts should strive to increase coverage, provide a wide range of contraceptive methods and improve the quality of care; women should have access to counseling and be able to switch methods easily when needed.
In 2012, at the Family Planning 2020 Summit in London, the Nigerian government made a commitment to increase the contraceptive prevalence rate to $36 \%$ by 2018 and to raise total spending on reproductive health commodities from US $\$ 12$ million to US $\$ 45.4$ million by $2016 .^{25}$ While this step is laudable, achieving the goal of $36 \%$ will require not only that the government fulfill its financial commitment, but, equally importantly, that it be strategic in its choices of programs to pursue. The government of Ethiopia has shown, with its very successful Health Extension Program, that such a strategy is possible. ${ }^{26}$ The Nigerian government should carry out an assessment to identify the types of programs that will work best in the Nigerian context.

Because it typically takes time to see the effects on personal behavior of even the best policies and programs, and because contraceptive failures happen even among users of modern methods, some women will still seek unsafe abortions, at least in the short run. To help such women avoid long-term disability and even death, the government should continue to increase and improve access to appropriate, adequate and timely postabortion care services. Such efforts should focus on providing access to modern, appropriate and relatively noninvasive methods of postabortion care, such as manual vacuum aspiration and misoprostol; providing adequate training for relevant cadres of health providers; legally permitting and equipping midlevel health practitioners to provide postabortion care; and training providers to treat clients in a nonjudgmental manner. In addition, although only a small number of women may be eligible for legal abortion under the current law, which permits abortion only to save a woman's life, an efficient process should be established to enable eligible women to have access to safe abortion services. To ensure that such abortions are performed safely, the government should promote training in the provision of safe abortion services at medical schools, during housemanship (postqualification training for young doctors, usually during their first two years) and during internships for medi-

\begin{tabular}{|c|c|c|c|c|c|c|c|c|c|}
\hline \multirow[t]{2}{*}{ Facility type } & \multirow[t]{2}{*}{$\mathrm{N}$} & \multirow{2}{*}{$\begin{array}{l}\text { Mean } \\
\text { no.of } \\
\text { beds }\end{array}$} & \multicolumn{7}{|l|}{$\%$} \\
\hline & & & $\begin{array}{l}\text { Provides } \\
\text { inpatient } \\
\text { services }\end{array}$ & $\begin{array}{l}\text { Provide } \\
\text { outpatient } \\
\text { services }\end{array}$ & $\begin{array}{l}\text { Has functional } \\
\text { MVA } \\
\text { equipment }\end{array}$ & $\begin{array}{l}\text { Has staff } \\
\text { trained } \\
\text { in MVA }\end{array}$ & $\begin{array}{l}\text { Has } \\
\text { surgical } \\
\text { ward }\end{array}$ & $\begin{array}{l}\text { Has separate } \\
\text { evacuation } \\
\text { ward }\end{array}$ & $\begin{array}{l}\text { Provides } \\
\text { induced } \\
\text { abortion }\end{array}$ \\
\hline \multicolumn{10}{|l|}{ Public/government ( $N=369$ ) } \\
\hline Teaching hospital/FMC & 47 & 272 & 100 & 100 & 98 & 98 & 100 & 84 & 14 \\
\hline General/specialist hospital & 171 & 84 & 100 & 99 & 85 & 88 & 100 & 45 & 7 \\
\hline Cottage hospital/CHC/clinic & 78 & 20 & 85 & 92 & 50 & 61 & 35 & 9 & 1 \\
\hline Maternity center & 73 & 6 & 87 & 98 & 10 & 22 & 4 & 3 & 4 \\
\hline \multicolumn{10}{|l|}{ Private $(\mathrm{N}=403)^{*}$} \\
\hline Hospital & 263 & 28 & 99 & 100 & 72 & 78 & 96 & 31 & 8 \\
\hline Clinic/medical center & 68 & 15 & 99 & 97 & 83 & 90 & 93 & 14 & 21 \\
\hline Maternity center & 72 & 13 & 97 & 97 & 62 & 75 & 68 & 15 & 7 \\
\hline All & 772 & 31 & 96 & 98 & 62 & 70 & 71 & 23 & 8 \\
\hline
\end{tabular}




\begin{tabular}{|c|c|c|c|c|c|c|c|c|}
\hline \multirow[t]{2}{*}{ Respondent } & \multirow[t]{2}{*}{$\mathrm{N}$} & \multicolumn{6}{|c|}{ Geopolitical zone } & \multirow[t]{2}{*}{ All } \\
\hline & & $\begin{array}{l}\text { North } \\
\text { West }\end{array}$ & $\begin{array}{l}\text { North } \\
\text { East }\end{array}$ & $\begin{array}{l}\text { North } \\
\text { Central }\end{array}$ & $\begin{array}{l}\text { South } \\
\text { West }\end{array}$ & South & South & \\
\hline \multicolumn{9}{|l|}{ Health Facilities Survey } \\
\hline Physician/medical officer & 404 & 50.4 & 21.9 & 48.6 & 62.2 & 71.4 & 69.4 & 52.3 \\
\hline Nurse/midwife & 252 & 35.9 & 43.2 & 33.3 & 28.1 & 27.7 & 24.1 & 32.6 \\
\hline CHEW/CHO & 111 & 13.7 & 32.9 & 17.4 & 8.9 & 0.8 & 6.5 & 14.4 \\
\hline Other & 5 & 0.0 & 1.9 & 0.7 & 0.7 & 0.0 & 0.0 & 0.6 \\
\hline Total & 772 & 100.0 & 100.0 & 100.0 & 100.0 & 100.0 & 100.0 & 100.0 \\
\hline \multicolumn{9}{|l|}{ Health Professionals Survey } \\
\hline Physician & 57 & 13.9 & 38.5 & 20.7 & 16.7 & 37.0 & 40.0 & 29.4 \\
\hline Other medical professional & 47 & 36.1 & 15.4 & 27.6 & 33.3 & 7.4 & 26.7 & 24.2 \\
\hline Program manager/health administrator & 23 & 13.9 & 7.7 & 10.3 & 16.7 & 22.2 & 6.7 & 11.9 \\
\hline Policymaker/politician/lawyer/judge/activist & 29 & 16.7 & 15.4 & 13.8 & 16.7 & 18.5 & 15.6 & 16.0 \\
\hline Lecturer/teacher/researcher & 31 & 16.7 & 17.9 & 24.1 & 16.7 & 11.1 & 6.7 & 14.9 \\
\hline Other & 7 & 2.8 & 5.1 & 3.4 & 0.0 & 3.7 & 4.4 & 3.6 \\
\hline Total & 194 & 100.0 & 100.0 & 100.0 & 100.0 & 100.0 & 100.0 & 100.0 \\
\hline
\end{tabular}

\begin{tabular}{|c|c|c|c|c|c|c|c|c|}
\hline \multirow[t]{2}{*}{ Level of training } & \multirow[t]{2}{*}{$\mathrm{N}$} & \multicolumn{4}{|c|}{ Government } & \multicolumn{3}{|l|}{ Private $^{*}$} \\
\hline & & $\begin{array}{l}\text { Teaching } \\
\text { hospital/ } \\
\text { FMC }\end{array}$ & $\begin{array}{l}\text { General/ } \\
\text { specialist } \\
\text { hospital }\end{array}$ & $\begin{array}{l}\text { Cottage } \\
\text { hospital/ } \\
\text { CHC/clinic }\end{array}$ & $\begin{array}{l}\text { Maternity } \\
\text { center }\end{array}$ & Hospital & $\begin{array}{l}\text { Clinic/ } \\
\text { Medical } \\
\text { center }\end{array}$ & $\begin{array}{l}\text { Maternity } \\
\text { center }\end{array}$ \\
\hline Physician/medical officer & 404 & 72 & 45 & 26 & 4 & 70 & 66 & 55 \\
\hline Nurse/midwife & 252 & 26 & 49 & 50 & 35 & 25 & 19 & 20 \\
\hline $\mathrm{CHEW} / \mathrm{CHO}$ & 111 & 2 & 5 & 24 & 58 & 5 & 15 & 24 \\
\hline Other & 5 & 0 & 1 & 0 & 3 & 0.4 & 0 & 0 \\
\hline Total & 772 & 100 & 100 & 100 & 100 & 100 & 100 & 100 \\
\hline
\end{tabular}

cal students and personnel. Steps should also be taken to ensure that women seeking legal abortions have access to the procedure as early as possible, so that they can benefit from the use of modern, less invasive methods.

When women and couples begin to want smaller families-and continue to be motivated to space their births and avoid premarital childbearing-they will use a combination of means, such as modern or traditional contraceptive methods and abortion, to achieve their goals. ${ }^{27}$ Unless adequate measures are taken to prevent unwanted pregnancy and unsafe abortion, the health and well-being of women will continue to be at risk in Nigeria.

\section{REFERENCES}

1. Center for Reproductive Rights, Nigeria's abortion provisions, no date, http://reproductiverights.org/en/world-abortion-laws/nigeriasabortion-provisions.

2. World Health Organization (WHO), Unsafe Abortion: Global and Regional Estimates of the Incidence of Unsafe Abortion and Associated Mortality in 2008, Geneva: WHO, 2011.

3. Henshaw SK et al., The incidence of induced abortion in Nigeria, International Family Planning Perspectives, 1998, 24(4):156-164.

4. Sedgh $\mathrm{G}$ et al., Unwanted pregnancy and associated factors among
Nigerian women, International Family Planning Perspectives, 2006, 32(4):175-184

5. Government of the Federal Republic of Nigeria, Nigeria Millennium Development Goals Report 2010, Abuja, Nigeria: Government of the Federal Republic of Nigeria, 2010.

6. Singh S, Prada E and Juarez F, The abortion incidence complications method: a quantitative technique, in: Singh S, Remez L and Tartaglione A, eds., Methodologies for Estimating Abortion Incidence and Abortion-Related Morbidity: A Review, New York: Guttmacher Institute, 2011

7. Sedgh $\mathrm{G}$ et al., Estimating abortion incidence in Burkina Faso using two methodologies, Studies in Family Planning, 2011, 42(3):147-154.

8. Juarez F and Singh S, Incidence of induced abortion by age and state, Mexico, 2009: new estimates using a modified methodology, International Perspectives on Sexual and Reproductive Health, 2012 , 38(2):58-67.

9. Sedgh $\mathrm{G}$ et al., Estimates of the incidence of induced abortion and consequences of unsafe abortion in Senegal, International Perspectives on Sexual and Reproductive Health, 2015, 41(1):11-19.

10. National Population Commission and ICF International, Nigeria Demographic and Health Survey 2013, Abuja, Nigeria: National Population Commission; and Rockville, MD, USA: ICF International, 2014.

11. Population Division, United Nations (UN) Department of Economic and Social Affairs, World Population Prospects: The 2012 Revision, New York: UN, 2013. 
12. Abdulkadir A et al., Medical record system in Nigeria: observations from multicentre auditing of radiographic requests and patients' information documentation practices, Journal of Medicine and Medical Science, 2011, 2(5):854-858.

13. Prada E, Biddlecom A and Singh S, Induced abortion in Colombia: new estimates and change between 1989 and 2008, International Perspectives on Sexual and Reproductive Health, 2011, 37(3):114-124

14. Iyioha IO and Nwabueze RN, eds., Comparative Health Law and Policy: Critical Perspectives on Nigerian and Global Health Law, Surrey, UK: Ashgate Publishing, 2015.

15. Okonofua FE et al., Perceptions of policymakers in Nigeria toward unsafe abortion and maternal mortality, International Perspectives on Sexual and Reproductive Health, 2009, 35(4):194-202.

16. Bongaarts J and Potter RG, Fertility, Biology, and Behavior: An Analysis of the Proximate Determinants, New York: Academic Press, 1983.

17. Leridon H, Human Fertility: The Basic Components, Chicago, IL, USA: University of Chicago Press, 1977.

18. WHO et al., Trends in Maternal Mortality: 1990 to 2013. Estimates by WHO, UNICEF, UNFPA, The World Bank and the United Nations Population Division, Geneva: WHO, 2014.

19. Bankole A et al., Unwanted Pregnancy and Induced Abortion in Nigeria: Causes and Consequences, New York: Guttmacher Institute, 2006.

\section{APPENDIX: METHODOLOGICAL DETAILS OF CALCULATING ABORTION INCIDENCE IN NIGERIA}

In this appendix, we present details regarding some of the adjustments and calculations we made in estimating the number of induced abortions in Nigeria.

\section{Adjustments to Postabortion Care Caseload}

Because the collection and initial analyses of data from the Health Facilities Survey identified clear patterns of misreporting, and one case of inadequate sample representation, we made several adjustments to the estimates of the number of women treated in health facilities for complications of abortion.

-Adjustment for misreporting of abortions. The first probable indication of substantial misreporting was the observation during fielding of the Health Facilities Survey that respondents were reporting very low numbers of induced abortions, even in the types of facilities generally known to be large providers of these services. This reluctance to provide information on induced abortion, but not on postabortion care, continued throughout fieldwork, despite efforts to reassure respondents that the information they provided would be kept confidential. On the basis of findings from the 1996 Nigerian abortion incidence study ${ }^{1}$ and from other incidence studies in the region (e.g., in terms of typical case loads for given sizes and types of facilities), we concluded that because induced abortion is highly restricted in Nigeria, many abortion procedures were being provided clandestinely (mainly in private facilities), and that many induced abortion services were being reported as postabortion care services, resulting in underreporting of the former and overreporting of the latter.

For example, in the 1996 study, the ratio of reported
20. Henshaw SK et al., Severity and cost of unsafe abortion complications treated in Nigerian hospitals, International Family Planning Perspectives, 2008, 34(1):40-50.

21. Prada E et al., Maternal near-miss due to unsafe abortion and associated short-term health and socioeconomic consequences in Nigeria, African Journal of Reproductive Health, 2015, 19(2):52-62.

22. Bankole A et al., Estimating the cost of post-abortion care in Nigeria: a case study, in: Lule E, Singh S and Chowdhury SA, eds., Fertility Regulation Behaviors and Their Costs, Washington, DC: World Bank, 2007.

23. National Population Commission, Nigeria and ICF Macro, Nigeria Demographic and Health Survey 2008, Abuja, Nigeria: National Population Commission and ICF Macro, 2009.

24. Sedgh G and Hussain R, Reasons for contraceptive nonuse among women having unmet need for contraception in developing countries, Studies in Family Planning, 2014, 45(2):151-169.

25. British Directorate for International Development (DFID) and the Bill and Melinda Gates Foundation, London Summit on Family Planning: Summaries of Commitments, London: DFID, 2012, https:// www.gov.uk/government/uploads/system/uploads/attachment_ data/file/67328/london-summit-family-planning-commitments.pdf.

26. Olson DJ and Piller A, Ethiopia: an emerging family planning success story, Studies in Family Planning, 2013, 44(4):445-459.

27. Berer M, Making abortions safe: a matter of good public health policy and practice, Bulletin of the World Health Organization, 2000, 78(5):580-592.

postabortion care cases to reported abortion cases in private facilities was 51:49. In 2012, the ratio was 90:10. Because we had no information suggesting that private facilities across Nigeria had stopped providing abortions (on the contrary, anecdotal evidence indicates that abortion continues to be a commonly provided service at these facilities), we assumed that the ratio had not changed since 1996. To correct for this misreporting, we adjusted the 2012 data to reflect the 1996 case ratio of abortion to postabortion care.

- Adjustment for reference period length. We made a second adjustment to take into account an unexpected consequence of using a shorter reference period in the Health Facilities Survey than is typically used in the Abortion Incidence Complications Methodology (AICM). For the first time in an AICM study, the 2012 Nigerian Health Facilities Survey asked respondents to estimate the number of postabortion care cases treated at their facility in a week; if they were not able to do so (probably because the caseload was small or they tended to assess caseloads in terms of a longer duration), they were asked to report the number of cases in a month or, if they preferred, in a year. The standard AICM approach only asks the respondent to provide estimates for a month or year; we added the shorter reference period (one week) because we thought respondents from larger facilities would find it easier to estimate for a shorter time period. Although respondents were asked to answer for one time period, several reported for multiple periods, which allowed us to compare the annual equivalents for these estimates. This check revealed that estimates of weekly caseloads yielded much higher annual totals than did estimates of monthly caseloads; for example, what would be a minor overestimation of one case in 
a weekly estimate would be inflated to 52 extra cases per year. In light of our earlier observation that facilities were overreporting postabortion care caseloads, we determined that facilities reporting estimates by the week were more likely than those reporting by the month to have contributed to the overestimation of postabortion care cases.

Given this pattern, and because this study was the first to use weekly reporting with the AICM methodology, we concluded that to achieve a close approximation to the standard approach of using monthly reporting, we must adjust the caseload for facilities that provided only weekly estimates. We therefore used the ratio of the annual total based on months to that based on weeks (among facilities for which data for both reference periods were available) to adjust downward the annual totals for facilities with only weekly data. This resulted in a $24 \%$ reduction in the number of postabortion care cases from the unadjusted national total.

- Adjustment for high caseloads in the North East. An additional adjustment was made only to data from the North East zone, where average postabortion care caseloads were notably higher than the caseloads at facilities with similar capacities in other zones, including the North West, which is the zone most similar to the North East in terms of residents' socioeconomic and demographic characteristics. To correct for this anomaly, we reduced postabortion care caseload estimates for the North East so that the ratio of average caseload to average number of beds equaled that of facilities in the same category in the North West zone.

-Adjustment for underrepresentation of public facilities in the South East. A fourth adjustment was made only for the South East zone, where public facilities were poorly represented in the Health Facilities Survey, resulting in exceptionally low average postabortion care caseloads in this sector. To correct for this, we adjusted the caseloads so that the ratio of the average number of postabortion care cases to the average number of beds in each type of public facility in the zone was similar to the ratio in the South West and South South zones combined. Again, we took this step because the South West and South South zones are most similar to the South East in terms of their sociocultural and demographic profiles.

- Overall effect of adjustments. In total, the adjustments described above reduced the number of reported postabortion care cases by $43 \%$. We acknowledge that the assumptions behind these adjustments are a limitation of our analysis. However, the adjustments were made using the best available information about abortion service provision, drawing on detailed information from the 1996 study and on our understanding of the context of abortion and postabortion service provision in the country. In addition, the direction of possible bias that may result from these adjustments is clear. The adjustment to public facility caseloads in the South East, which had the smallest impact on our overall estimates, led to an increase in the number of postabortion cases, and an increase in the estimate of abortion incidence for that zone. The remaining three adjust- ments resulted in lower postabortion caseloads, and hence lower rather than higher estimates of abortion incidence. Furthermore, without these adjustments, the resulting estimated abortion rates would have been too high to be realistic or defensible, given other relevant evidence from Nigeria and West Africa, including estimates of abortion incidence and fertility and contraceptive behavior.

\section{Calculation of the Multipliers}

Health professionals who took part in the Health Professionals Survey were asked to make several estimates, in cluding the percentage distribution of women who had abortions according to the type of provider they used; the proportion of these women who had complications, according to the type of provider they used; and the proportion of women with complications who obtained care from a health facility. Recognizing that the circumstances under which women obtain abortions in Nigeria vary by women's area of residence and socioeconomic status, we asked survey participants to provide the aforementioned estimates separately for four subgroups of women: urban poor, urban nonpoor, rural poor and rural nonpoor. Because medical and nonmedical respondents have somewhat different areas of expertise concerning abortion service provision and may provide different estimates of these parameters, we calculated estimates separately for the two groups and used the unweighted average of the results.

The estimates from the health professionals were weighted by the relative size of the four subgroups of women. We then calculated the multiplier (see main article) for each geopolitical zone as the inverse of the estimated proportion of abortion recipients in the zone who received care in health facilities for complications. In mathematical terms, calculation of the multiplier would be expressed in the following terms:

Suppose:

$\mathrm{A}_{\mathrm{jk}}=\%$ of women who have an abortion complication, by subgroup

$\mathrm{B}_{\mathrm{jk}}=\%$ of women with complications who obtain care in a health facility, by subgroup

$\mathrm{C}_{\mathrm{jk}}=\%$ obtaining treatment for complications in a health facility, among all women having abortions, by subgroup

$\mathrm{W}=$ distribution of the population of women according to subgroup

Where:

$\mathrm{j}=$ subgroup (rural poor, rural nonpoor, urban poor, urban nonpoor) and

$\mathrm{k}=$ type of respondent (medical/nonmedical)

Then:

$\mathrm{C}_{\mathrm{jk}}=\left(\mathrm{A}_{\mathrm{jk}} * \mathrm{~B}_{\mathrm{jk}}\right)$

$D=\operatorname{Sum}\left(W^{*} C_{j k}\right)$ (i.e., weighted \% of women who had an abortion who received treatment)

Multiplier $(\mathrm{M})=1 / \mathrm{D}$ 


\section{RESUMEN}

Contexto: Debido a la baja prevalencia de uso de anticonceptivos en Nigeria, un importante número de mujeres tienen embarazos no planeados, muchos de los cuales se resuelven a través de abortos clandestinos a pesar de la restrictiva ley de aborto del país. Es necesario contar con estimaciones actualizadas de la incidencia del aborto.

Métodos: Se aplicó una metodología indirecta ampliamente utilizada para estimar la incidencia del aborto y del embarazo no planeado en Nigeria en 2012. Se recolectaron datos sobre la provisión de servicios de aborto y postaborto a partir de una muestra representativa a nivel nacional de 772 instituciones de salud, y se obtuvieron estimaciones de la probabilidad de que las mujeres que tienen abortos inseguros experimenten complicaciones y reciban tratamiento, a partir de 194 profesionales de la salud con un amplio conocimiento del contexto del aborto en Nigeria.

Resultados: Se estima que en 2012 ocurrieron en Nigeria alrededor de 1 millón 250 mil abortos inducidos, lo que equivale a una tasa de 33 abortos por 1,000 mujeres en edades de 15 a 49 años. La tasa estimada de embarazos no planeados fue de 59 por 1,000 mujeres en edades de 15 a 49 años. El cincuenta y seis por ciento de los embarazos no planeados se resolvió recurriendo al aborto. Cerca de 212,000 mujeres recibieron tratamiento por complicaciones de abortos inseguros, lo que representa una tasa de tratamiento de 5.6 por 1,000 mujeres en edad reproductiva; y otras 285,000 mujeres experimentaron graves consecuencias para su salud, pero no recibieron el tratamiento que necesitaban.

Conclusión: Los niveles de embarazo no planeado y de aborto inseguro continúan siendo altos en Nigeria. Las mejoras en el acceso a los servicios de anticoncepción, así como en la provisión de servicios de aborto seguro y de atención postaborto (según lo permita la ley), pueden ayudar a reducir la morbilidad y mortalidad materna.

\section{RÉSUMÉ}

Contexte: La faible prévalence contraceptive au Nigéria fait que beaucoup de femmes se trouvent confrontées à des grossesses non planifiées, souvent interrompues clandestinement, en dépit de la législation restrictive de l'avortement dans le pays. L'incidence actuelle de l'avortement doit être estimée.

Méthodes: Une méthodologie indirecte largement pratiquée a servi à estimer l'incidence de l'avortement et de la grossesse non planifiée au Nigéria en 2012. Les données relatives à la prestation de l'avortement et de soins après avortement ont été collectées auprès d'un échantillon nationalement représentatif de 772 établissements de santé. Les estimations de la probabilité de complications de l'avortement non médicalisé et d'obtention de soins l'ont été auprès de 194 professionnels de la santé généralement au courant du contexte de l'avortement au Nigéria.

Résultats: On estime à 1,25 million le nombre d'avortements provoqués au Nigéria en 2012, soit un taux de 33 IVG pour 1000 femmes âgées de 15 à 49 ans. Pour ce qui est des grossesses non planifiées, le taux est estimé à 59 pour 1000 femmes âgées de 15 à 49 ans. Cinquante-six pour cent des grossesses non planifiées sont interrompues. Environ 212000 femmes ont été traitées pour complications d'un avortement non médicalisé, soit un taux de traitement de 5,6 pour 1000 femmes en âge de procréer, tandis que 285000 autres souffraient de conséquences de santé graves sans toutefois obtenir les soins nécessaires.

Conclusion: Les taux de grossesse non planifiée et d'avortement non médicalisé restent élevés au Nigéria. L'amélioration de l'accès aux services de contraception et de la prestation de services d'avortement médicalisé et de soins après avortement (dans la mesure permise par la loi) pourrait aider à réduire la morbidité et la mortalité maternelles.

\section{Acknowledgments}

The authors gratefully acknowledge comments and feedback provided on earlier drafts of this paper by Dee Wulf. The authors also thank Calvin Chama, Emily Nzeribe, A.O. Oguntayo, Anthony Okonkwo and Rakiya Saidu for coordinating and supervising the data collection process. This study was supported by funding from the Dutch Ministry of Foreign Affairs, the UK Government and The John D. and Catherine T. MacArthur Foundation. The findings and conclusions in this article do not necessarily reflect the positions and policies of the donors.

Author contact: abankole@guttmacher.org 